\title{
ANALISIS FAKTOR YANG MEMPENGARUHI KEPUTUSAN PEMBELIAN KONSUMEN TERHADAP PRODUK RABBANI DI BUNKER RABBANI PUCANG SURABAYA
}

\author{
Mariska Pradnya Paramitha \\ Mahasiswa Program Studi S-1 Ekonomi Islam - Fakultas Ekonomi dan Bisnis - Universitas \\ Airlangga \\ pradnyamariska@gmail.com \\ Fatin Fadhilah Hasib \\ Departemen Ekonomi Syariah - Fakultas Ekonomi dan Bisnis - Universitas Airlangga \\ Email: fatin.fadhilah@gmail.com
}

\begin{abstract}
This research aims to identify factors affecting consumer buyer decision to buy Rabbani products in Bunker Rabbani Pucang Branch Surabaya, amid burgeoning hijab trend fashion and competitive pressure from other retailers of moslem clothing products.

In our study we employed quantitative approach, which followed by analysis using exploratory analysis factor. The sample population that we studied comprised of female customers buying Rabbani products in the above retailer, which we surveyed by using simple random sampling. The primary data collection is conducted in two stages: pre-test and main test, whereas secondary data are obtained elsewhere from literature. The pre-test was carried out by posing the questionnaire to 30 respondents. The result of pre-test is subsequently used as instrument indicator for main test which involving 91 respondents.

From our investigation we obtained three factors behind consumer buyer decision to buy Rabbani products in the store used as case study: factor of product types, factor of price and store location, and factor of store promotion. Based on this result we thus provide suggestion to Rabbani store to keep up product attribute existence amid burgeoning hijab trend fashion and competitive pressure from other retailers of moslem clothing products.
\end{abstract}

Key words: buying decision, Rabbani products, store promotion, price and store location.

\section{PENDAHULUAN}

Manusia adalah mahkluk ciptaan Allah SWT yang memiliki berbagai jenis kebutuhan yang harus dipenuhinya demi bertahan hidup. Ada tiga macam kebutuhan pokok manusia yaitu pangan, sandang dan papan. Ketiga kebutuhan ini adalah kebutuhan dasar yang jika tidak terpenuhi, manusia tidak akan dapat bertahan hidup. Sandang atau pakaian adalah salah satu kebutuhan pokok manusia yang wajib terpenuhi. Manusia, pria maupun wanita tidak mungkin hidup tanpa menggunakan sandang. Terutama bagi wanita Islam atau muslimah, wajib untuk menutup auratnya. Perintah ini tercantum dalam surat Al-A'raf 26 dan AlAhzab 59.

Dewasa ini busana muslim tidak hanya berperan sebagai sarana beribadah dalam rangka mengamalkan ajaran agama, tetapi juga berfungsi untuk mempercantik penampilan muslimah, yaitu berbusana sesuai kaidah namun tetap modis. Desain busana muslim tidak lagi konservatif tapi lebih kontemporer dan berjiwa muda sehingga lebih diminati mulai dari kalangan wanita dewasa 
hingga remaja putri. Selain itu, maraknya komunitas hijab dan peragaan busana muslim juga menjadi faktor yang membuat industri fashion muslim semakin berkembang (Noorastuti dan Abbdinnah, Viva Life, 2012).

Perkembangan bisnis busana muslimah dalam dua dekade terakhir terlihat lebih dinamis dan kreatif. Seperti yang diungkapkan Manajer Kriya Pustaka, Yuni Harlinawati, hal tersebut ditandai dengan kehadiran beberapa perancang muda dengan sentuhan desain urban yang unik tetapi simple sehingga nyaman digunakan diberbagai aktivitas (Burhani, Antara News, 2012). Salah satu pemain dalam industri busana muslim yang tetap eksis hingga saat ini ditengah ketatnya persaingan bisnis dan trend fashion hijab adalah Rabbani. Bisnis utama Rabbani adalah kerudung instan.

Rabbani berusaha untuk mengikuti trend, tetapi tetap belum dapat mengikuti trend yang sedang populer saat ini dimasyarakat. Rabbani tidak terlalu banyak melakukan pengembangan model pada produknya, karena memiliki pakem tersendiri dalam desainnya. Salah satu gerai Rabbani berlokasi di Jalan Pucang Anom No.33 Surabaya. Gerai ini disebut sebagai bunker atau bangunan kerudung. Penelitian akan dilakukan di gerai tersebut untuk mengetahui faktor apa saja yang mempengaruhi konsumen melakukan keputusan pembelian terhadap produk-produk Rabbani ditengah menjamurnya trend fashion hijab dan retail busana muslim yang memasarkan produk serupa.

Berdasarkan latar belakang yang telah diuraikan sebelumnya dan melihat fenomena yang ada, maka peneliti tertarik untuk melakukan penelitian yang berjudul "Analisis Faktor yang Mempengaruhi Keputusan Pembelian Konsumen terhadap Produk Rabbani di Bunker Rabbani Pucang Surabaya.". Rumusan masalah penelitian ini adalah faktor apa saja yang mempengaruhi keputusan pembelian konsumen terhadap produk Rabbani di Bunker Rabbani Pucang Surabaya?. Tujuan penelitian adalah untuk menjawab rumusan masalah yaitu mengetahui faktor apa saja yang mempengaruhi keputusan pembelian konsumen terhadap produk Rabbani di Bunker Rabbani Pucang Surabaya.

\section{Landasan Teori}

\section{Keputusan Pembelian Konsumen}

Pembelian adalah keputusan konsumen mengenai apa yang dibeli, apakah membeli atau tidak, kapan membeli, dimana membeli dan bagaimana cara pembayarannya. Keputusan konsumen ini merupakan tindakan dari dua atau lebih alternatrif (Sumarwan, dalam Wulandari, 2012:48). Keputusan merupakan pendekatan penyelesaian masalah yang terdiri dari pengenalan masalah, mencari informasi, beberapa penilaian alternatif, membuat keputusan pembelian dan perilaku setelah 
membeli yang dilalui oleh konsumen (Kotler, dalam Widagdo, 2011:3).

\section{Faktor yang Mempengaruhi Keputusan}

\section{Pembelian}

1. Bauran Pemasaran (Marketing Mix).

Menurut E. Jerome (dalam Wulandari, 2012:49) bauran pemasaran (marketing mix) adalah sebuah perangkat alat pemasaran taktis yang terkontrol dan dipadukan oleh perusahaan untuk menghasilkan respon yang diinginkan pasar yang terdiri dari empat komponen dasar yaitu product, price, promotion, place (4 P).

2. Celebrity Endorser

Selebriti sering dimanfaatkan sebagai endorser karena dirasa lebih dapat mempengaruhi psikologis konsumen. Mereka memiliki daya tarik (attractiveness) dan kredibilitas (credibility) yang menjadi keunikan tersendiri (Sebayang dan Siahaan, 2008:118).

3. Citra Merek (Brand Image)

Citra merek adalah kepercayaan dan penglihatan yang tersimpan dalam benak konsumen sebagai bentuk cerminan asosiasi di ingatan konsumen (Kotler, dalam Rizan dkk., 2012:5).

4. Kepercayaan Merek (Brand Trust) Brand trust adalah kesediaan konsumen untuk mempercayai suatu merek dengan segala resikonya karena adanya harapan dalam benak mereka bahwa merek tersebut akan memberikan hasil yang positif sehingga akan menimbulkan kesetiaan terhadap suatu merek (Rizan dkk., 2012:6).

5. Kualitas Pelayanan (Service Quality) Kualitas pelayanan merupakan tingkat keunggulan atau excellence yang diharapakan dan pengendalian atas keunggulan tersebut untuk memenuhi keinginan konsumen (Tjiptono, dalam Widagdo, 2011:2). Terdapat lima dimensi utama service quality menurut Parasuraman et al (dalam Tjiptono, 2005:273) yaitu:

a. Reliabilitas (reliability) yaitu kemampuan memberikan layanan yang dijanjikan dengan segera, akurat, dan memuaskan.

b. Daya tanggap (responsiveness) yaitu keinginan para staf untuk membantu para pelanggan dan memberikan layanan dengan tanggap.

c. Jaminan (assurance) mencakup pengetahuan, kompetensi, kesopanan dan sifat dapat dipercaya yang dimiliki para staf, bebas dari bahaya, resiko atau keraguraguan.

d. Empati (empathy) meliputi kemudahan dalam menjalin relasi, komunikasi yang baik, perhatian pribadi dan pemahaman atas kebutuhan individual para pelanggan.

e. Bukti fisik (tangibles) meliputi fasilitas fisik, perlengkapan, pegawai dan sarana komunikasi.

6. Atribut Produk 
Menurut Kotler (dalam Hidayat, 2012:5) atribut produk merupakan pengembangan suatu produk atau jasa melibatkan penentuan manfaat yang akan diberikan kepada konsumen. Manfaat tersebut dikomunikasikan dan diserahkan pada konsumen melalui atribut produk yang terdiri dari kualitas, fitur dan desain ( rancangan ).

7. Atmosfer Toko (Store Atmosphere) Atmosfer toko merupakan kombinasi pesan secara fisik yang telah direncanakan dan digambarkan sebagai perubahan terhadap perencanaan lingkungan pembelian yang menghasilkan efek emosional khusus yang dapat menyebabkan konsumen melakukan tindakan pembelian (Gilbert, dalam Dessyana, 2013:846).

\section{Perilaku Konsumen Muslim}

Perilaku konsumen muslim harus mencerminkan hubungan antara dirinya dengan Allah SWT. Bentuk belanja seharihari dari konsumen muslim adalah manifestasi zikir dirinya atas nama Allah SWT yaitu dengan memilih jalan yang dibatasi oleh Allah SWT seperti tidak memilih barang yang haram, tidak kikir dan tidak tamak agar selamat dunia dan akhirat (Muflih, 2006:4).

\section{Unsur Manusia dan Pengaruhnya Terhadap Perilaku Konsumen Muslim}

Manusia terdiri atas empat unsur yaitu, ruh, nafs, aql' dan qalb. Masing- masing unsur tersebut memiliki karakteristik yang berbeda tetapi saling berhubungan dan membentuk karakteristik seseorang. Aql' merupakan rasio yang digunakan sebagai alat berpikir mausia agar manusia dapat berpikir secara rasional. Qalb merupakan rasa yang mengendalikan perasaan manusia. Nafs adalah jiwa manusia dan berbeda dengan jiwa yang dimiliki oleh tumbuhtumbuhan dan hewan (Al-Ghazali, dalam Muflih, 2006:51).

\section{Model Analisis}

Gambar dibawah menjelasakan model analisis dari penelitian ini, yaitu P1 hingga P13 adalah faktor-faktor yang mempengaruhi konsumen membeli produk Rabbani di Bunker Rabbani Pucang Surabaya yang diperoleh dari tes pertama (pre test). Faktor-faktor ini selanjutnya akan direduksi menjadi faktor F1 hingga Fn menggunakan analisis faktor eksploratori.

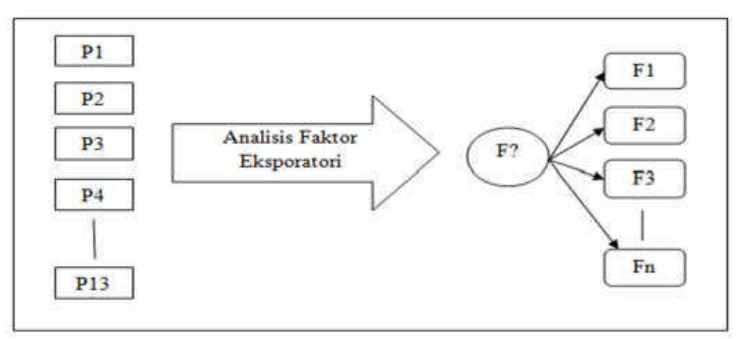

Sumber : Dartistiana, Nabiya Carissa. 2013. Hal 53. Faktor yang Mempengaruhi Keputusan Mahasiswa Memilih Program Studi SI Ekonomi Islam Fakultas Ekonomi dan Bisnis Universitas Airlangga. Skripsi tidak diterbitkan. Fakultas Ekonomi dan Bisnis Universitas Airlangga. (diolah).

\section{Pendekatan Penelitian}


Pendekatan penelitian yang digunakan adalah pendekatan kuantitatif. Strategi analisis yang digunakan adalah analisis faktor eksploratori. Analisis faktor eksploratori digunakan untuk melihat berapa banyak faktor yang dibutuhkan untuk menjelaskan hubungan diantara seperangkat indikator dengan mengamati besarnya muatan faktor (Gable, dalam Yusrizal, 2008:79).

\section{Identifikasi Variabel}

Terdapat 13 indikator yang direduksi menjadi faktor atau variabel dalam penelitian ini.

\section{Definisi Operasional}

Berdasarkan hasil pre test yang dilakukan pada 30 responden wanita, dirumuskan 13 indikator beserta definisi operasionalnya yang mempengaruhi keputusan konsumen membeli produk Rabbani di Bunker Rabbani Pucang Surabaya yaitu :

1. Model produk sesuai syariah (P1) adalah produk-produk Rabbani sesuai aturan syariah sehingga dengan mengenakan produk Rabbani berarti telah berbusana muslim sesuai aturan syariah.

2. Model produk Rabbani memiliki beragam variasi warna, corak dan motif serta up to date (P2) adalah model produk Rabbani memiliki beragam variasi warna, corak dan motif serta mengikuti trend fashion.

3. Logo Rabbani di setiap produknya (P3) adalah Rabbani selalu mencantumkan logo di setiap produknya sehingga produkproduk Rabbani mudah dikenali dan memiliki ciri khas.

4. Variasi produk untuk usia anakanak, remaja hingga dewasa (P4) adalah Rabbani menyediakan produk untuk memenuhi kebutuhan konsumenya di segala usia, mulai dari usia anak-anak, remaja hingga dewasa.

5. Bahan produk berkualitas sehingga produknya nyaman dikenakan (P5) adalah bahan yang digunakan oleh Rabbani merupakan bahan yang berkualitas sehingga produknya nyaman dikenakan konsumen.

6. Promo diskon untuk member atau non member (P6) adalah Rabbani memberikan fasilitas diskon kepada konsumen yang menjadi member atau non member.

7. Harga produk terjangkau (P7) adalah harga produk-produk Rabbani di Bunker Rabbani Pucang Surabaya relatif terjangkau oleh konsumen.

8. Lokasi gerai strategis (P8) adalah lokasi Bunker Rabbani Pucang Surabaya strategis sehingga mudah dijangkau.

9. Fasilitas gerai yang lengkap, layak dan nyaman untuk konsumen. Hal ini dapat dilihat dari tersedianya fasilitas musholla dalam gerai, toilet yang bersih, tempat duduk tunggu dan halaman parkir memadai (P9) 
adalah Bunker Rabbani Pucang Surabaya menyediakan fasilitas yang lengkap, layak dan membuat konsumen merasa nyaman berbelanja berupa fasilitas musholla, toilet, tempat duduk tunggu dan halaman parkir yang luas.

10. Pelayanan yang ramah (P10) adalah Bunker Rabbani Pucang Surabaya memberikan pelayanan (service quality) yang ramah kepada konsumen.

11. Menjadi member Rabbani (P11) adalah konsumen tertarik membeli produk Rabbani di Bunker Rabbani Pucang Surabaya karena sudah menjadi member dan memiliki kartu keanggotaan.

12. Gerai yang bersih dan display produk yang menarik sehingga memudahkan konsumen untuk berbelanja produk Rabbani (P12) adalah gerai Bunker Rabbani Pucang Surabaya selalu terjaga kebersihannya dengan display produk yang menarik sehingga membuat konsumen mudah untuk melihat, memeriksa dan memilih produk-produk Rabbani.

13. Rekomendasi dari teman (P13) adalah konsumen membeli produk Rabbani di Bunker Rabbani Pucang Surabaya atas saran dari teman.

Pengukuran variabel menggunakan skala Likert dalam sebuah kuisioner yang dilakukan pada saat main test. Skor yang diberikan untuk jawaban dari setiap item dalam instrumen penelitian ini adalah :

$\begin{array}{ll}\text { Sangat setuju } & \text { : skor } 5 \\ \text { Setuju } & \text { :skor } 4 \\ \text { Cukup } & \text { :skor } 3 \\ \text { Tidak setuju } & \text { : skor 2 } \\ \text { Sangat tidak setuju } & \text { : skor } 1\end{array}$

\section{Jenis dan Sumber Data}

Data primer dalam penelitian ini merupakan jawaban dari kuisioner yang disebarkan secara langsung kepada responden, yaitu konsumen Bunker Rabbani Pucang Surabaya.

Sedangkan data sekunder diperoleh dari pihak Bunker Rabbani Pucang Surabaya, browsing internet, dokumen dan sumber lain yang relevan.

\section{Populasi dan Sampel}

Populasi penelitian ini adalah konsumen yang pernah membeli produk Rabbani di Bunker Rabbani Pucang Surabaya. Jumlah sampel yang diambil untuk pre test penelitian ini sebanyak 30 responden, yang merupakan jumlah minimal sampel yang digunakan jika penelitian menggunakan perhitungan statistik (Champion, dalam Velany, 2008:27). Jumlah sampel untuk main test sebanyak 91 responden yang semuanya adalah wanita. 


\section{Prosedur Pengambilan Sampel}

Pengambilan

sampel

menggunakan simple random sampling. Jumlah 91 responden diperoleh dari 13 indikator dikali 7 (pilihan dari rentang angka 5-10). Jumlah sampel ideal untuk analisis faktor adalah antara 50-100 (Santoso, 2010:58).

\section{Teknik Pengumpulan Data}

Teknik pengumpulan data adalah pre test, studi pustaka, main test dan dokumentasi.

\section{Uji Validitas dan Reliabilitas}

Uji validitas menggunakan corrected item-total correlation, valid jika korelasi $(r)>0$ (Sugiyono, dalam Dartistiana, 2013:65). Uji reliabilitas menggunakan Croanbach Alpha, reliabel jika $a>0,6$ (Malhotra, 2009:310).

\section{Teknik Analisis Data}

Penelitian ini menggunakan teknik analisis faktor karena mencoba menemukan interrelationship (hubungan) antara sejumlah variabel yang saling independen satu sama lainnya, sehingga dapat dibuat kumpulan variabel yang lebih kecil dari jumlah variabel awal (Santoso, 2010:57). Pendekatan analisis faktornya adalah eksploratori karena ingin mengetahui berapa banyak faktor yang dibutuhkan untuk menjelaskan hubungan tersebut dengan melihat banyaknya muatan faktor.

\section{Hasil dan Pembahasan Penelitian}

\section{Analisis Data}

Teknik analisis data yang digunakan adalah analisis faktor eksploratori dengan menggunakan model Principal Component Analysis (PCA). Menurut Malhotra (2010:290) terdapat beberapa kunci statistik, antara lain Uji Bartlett's Sphericity yang berfungsi untuk menguji interdependensi antar variabel yang menjadi suatu faktor. Sedangkan Kaiser-Meyer Olkin (KMO) merupakan angka indeks yang membandingkan besarnya koefisien korelasi observasi dengan koefisien korelasi parsial. Apabila nilainya kurang dari 0,5 maka korealsi antar indikator tidak dapat menjelaskan indikator lain dan analisis faktor tidak sesuai untuk diterapkan.

\section{Tabel KMO dan Uji Bartlett's}

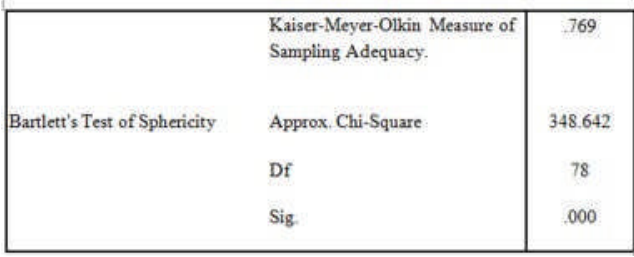

Berdasarkan tabel diatas, dapat dilihat bahwa nilai KMO Measure of Sampling Adequacy sebesar 0,769 yang berarti lebih besar dari 0,5. Nilai tersebut menunjukkan bahwa korealsi antar indikator dapat menjelaskan indikator lain dan analisis faktor sesuai untuk diterapkan. Sedangkan nilai signifikansinya kurang dari 0,05 yaitu sebesar 0,000, yang berarti bahwa indikator dalam penelitian ini sangat signifikan dan dapat dipercaya.

Korelasi matriks menunjukkan koefisien korelasi ( $r$ ) antara variabel satu dengan variabel lainnya dan memutuskan apakah variabel tersebut dapat 
diikutsertakan dalam analisis faktor atau tidak. Pada variabel P13, memiliki nilai MSA (Measure of Sampling Adequacy) sebesar 0,342 . Nilai tersebut kurang dari 0,5 sehingga variabel P13 tidak dimasukkan dalam perhitungan analisis faktor. Nilai komunalitas ditunjukkan dalam tabel PCA. Variabel P8 memiliki nilai tertinggi sebesar 0,812 yang berarti bahwa variabel ini akan berkorelasi erat dengan faktor yang akan terbentuk. Sedangkan nilai terendah dimiliki oleh variabel P10, yang berarti bahwa variabel ini akan berkorelasi paling rendah dengan faktor yang akan terbentuk.

Penentuan jumlah faktor menggunakan metode nilai eigen yang disajikan dalam tabel nilai eigen. Hanya yang memiliki nilai eigen $>1$ yang akan dimasukkan dalam analisis selanjutnya. Faktor yang memiliki nilai eigen $>1$ adalah faktor satu dengan nilai eigen sebesar 4,240, faktor dua dengan nilai eigen sebesar 1,571 dan faktor tiga dengan nilai eigen 1,180 .

Tabel Nilai

\begin{tabular}{|c|c|c|}
\hline Variabel & $\begin{array}{c}\text { Nilai Korelasi } \\
\text { (Anti Image })\end{array}$ & Keputusan \\
\hline P1 & 0,812 & Dapat dianalisis \\
\hline P2 & 0,789 & Dapat dianalisis \\
\hline P3 & 0,812 & Dapat dianalisis \\
\hline P4 & 0,779 & Dapat dianalisis \\
\hline P5 & 0,812 & Dapat dianalisis \\
\hline P6 & 0,747 & Dapat dianalisis \\
\hline P7 & 0,823 & Dapat dianalisis \\
\hline P8 & 0,662 & Dapat dianalisis \\
\hline P9 & 0,763 & Dapat dianalisis \\
\hline P10 & 0,849 & Dapat dianalisis \\
\hline P11 & 0,673 & Dapat dianalisis \\
\hline P12 & 0,835 & Dapat dianalisis \\
\hline P13 & 0,342 & Tidak dapat dianalisis \\
\hline
\end{tabular}

Tabel

\begin{tabular}{|c|c|}
\hline Variabel & Extraction \\
\hline P1 & 0,585 \\
\hline P2 & 0,543 \\
\hline P3 & 0,514 \\
\hline P4 & 0,604 \\
\hline P5 & 0,744 \\
\hline P6 & 0,679 \\
\hline P7 & 0,624 \\
\hline P8 & 0,812 \\
\hline P9 & 0,643 \\
\hline P10 & 0,393 \\
\hline P11 & 0,730 \\
\hline P12 & 0,536 \\
\hline P13 & 0,766 \\
\hline
\end{tabular}

Tabel Nilai Eigen

\begin{tabular}{|c|c|c|c|c|c|c|}
\hline \multirow[b]{2}{*}{ Composent } & \multicolumn{3}{|c|}{ Intital Eigetrvalues } & \multicolumn{3}{|c|}{ Extraction Sums of Squared Loadings } \\
\hline & Total & *of Variance & Cumulative \% & Total & \% of Varisoce & Cumulative \% \\
\hline 1 & 4240 & 35.331 & 35.331 & 4240 & 35.331 & $35.33 !$ \\
\hline 2 & 1571 & 13.096 & 48.427 & 1571 & 13.096 & 48.427 \\
\hline 3 & 1.180 & 9.834 & 58261 & 1.180 & 9.834 & 58261 \\
\hline 4 & 910 & 7.385 & 65.843 & & & \\
\hline 5 & 809 & 6.742 & 72585 & & & \\
\hline 6 & .740 & 6.163 & 78.748 & & & \\
\hline o & .671 & 5.592 & 84.339 & & & \\
\hline $\mathrm{s}$ & 475 & 3.957 & $\$ 8.296$ & & & \\
\hline 9 & .409 & 3.409 & 91.705 & & & \\
\hline 10 & 367 & 3.059 & 94764 & & & \\
\hline 11 & 348 & 2899 & 97.663 & & & \\
\hline 12 & 280 & 2337 & 100.000 & & & \\
\hline
\end{tabular}

Faktor matriks (dijelaskan dalam tabel komponen matriks) adalah faktor yang berisi muatan matriks dari semua variabel pada semua faktor yang telah dipilih. Dari faktor matriks ini dapat dilihat pengaruh variabel terhadap faktor. Hasil perhitungan komponen matriks disajikan dalam tabel dibawah. Komponen matriks dapat diinterpretasikan apabila memiliki nilai loading lebih dari 0,5 .

Tabel Rotasi Faktor dengan Varimax

\begin{tabular}{|l|c|c|c|}
\hline \multirow{2}{*}{} & \multicolumn{3}{|c|}{ Component } \\
\cline { 2 - 4 } & 1 & 2 & 3 \\
\hline P 1 & .749 & .068 & .080 \\
P 2 & .546 & .317 & .120 \\
P 3 & .587 & .289 &., 223 \\
P 4 & .742 & .128 & .100 \\
P 5 & .791 & .092 & .273 \\
P 6 & .123 & .182 & .802 \\
P 7 & .229 & .650 & .383 \\
P 8 & .001 & .879 & .007 \\
P 9 & .265 & .708 & .169 \\
P 10 & .346 & .443 & .111 \\
P 11 & .010 & .059 & .834 \\
P 12 & .244 & .450 & .517 \\
\hline
\end{tabular}


Tabel Komponen Matrix

\begin{tabular}{|c|c|c|c|}
\hline \multirow{2}{*}{} & \multicolumn{3}{|c|}{ Component } \\
\cline { 2 - 4 } & 1 & 2 & 3 \\
\hline P 1 & .573 & -.426 & .250 \\
P 2 & .608 & -.209 & .013 \\
P 3 & .469 & -.487 & -.141 \\
P 4 & .614 & -.394 & .213 \\
P 5 & .699 & -.312 & .352 \\
P 6 & .539 & .531 & .347 \\
P 7 & .715 & .263 & -.205 \\
P 8 & .541 & .196 & -.664 \\
P 9 & .682 & .098 & -.354 \\
P 10 & .548 & -.055 & -.157 \\
P 11 & .402 & .601 & .418 \\
P 12 & .660 & .304 & .027 \\
\hline
\end{tabular}

Tabel diatas menunjukkan faktor pertama memiliki 10 variabel dengan nilai loading diatas 0,5 yaitu $\mathrm{Pl}$,P2,P4,P5,P6,P7,P8,P9,P 10 dan P12. Faktor kedua memiliki dua variabel yaitu P6 dan P11. Sedangakan faktor ketiga belum memiliki variabel diatas 0,5 . Oleh karena itu selanjutnya harus dilakukan rotasi faktor dengan metode Varimax agar variabel tersebar secara berbeda. Penjelasan tabel hasil rotasi faktor dengan Varimax adalah sebagai berikut:

1. Faktor satu : Variabel P1,P2,P3,P4 dan P5 memiliki nilai loading diatas 0,5 .

2. Faktor dua : Variabel P7,P8 dan P9 memiliki nilai loading diatas 0,5 .

3. Faktor tiga : Variabel P6 dan P11 memiliki nilai loading diatas 0,5 .

Berdasarkan tabel diatas dapat dijelaskan bahwa faktor pertama yang mempengaruhi konsumen membeli produk Rabbani di Bunker Rabbani Pucang Surabaya adalah model produk sesuai aturan syariah (P1) dengan nilai loading 0,749, model produk Rabbani memiliki beragam variasi warna, corak dan motif serta up to date (P2) dengan nilai loading 0,546 , logo Rabbani di setiap produknya (P3) dengan nilai loading 0,587, variasi produk untuk usia anak-anak, remaja hingga dewasa (P4) dengan nilai loading 0,742, dan bahan produk berkualitas sehingga produknya nyaman dikenakan (P5) dengan nilai loading sebesar 0,791. Berdasarkan lima variabel yang telah disebutkan, maka faktor pertama diberi nama faktor produk.

Faktor kedua yang mempengaruhi konsumen adalah harga produk terjangkau ( $P$ 7) dengan nilai loading 0,650 , lokasi gerai strategis (P8) dengan nilai loading 0,879 , dan fasilitas gerai yang lengkap, layak dan nyaman untuk konsumen. Hal ini dapat dilihat dari tersedianya fasilitas musholla dalam gerai, toilet yang bersih, tempat duduk tunggu dan halaman parkir memadai (P9) memiliki nilai loading sebesar 0,708. Berdasarkan tiga variabel yang telah disebutkan, maka faktor ketiga dinamakan sebagai faktor harga dan tempat.

Faktor ketiga terdiri dari tiga variabel yaitu promo diskon untuk member atau non member (P6) dengan nilai loading 0,802, menjadi member Rabbani dan memiliki kartu keanggotaan (P11) dengan nilai loading 0,834 dan gerai yang bersih dan display produk yang menarik sehingga memudahkan konsumen untuk berbelanja produk Rabbani (P12) dengan nilai loading 0,517. Berdasarkan tiga variabel diatas, maka faktor ketiga 
dinamakan sebagai faktor store promotion.

\section{Uji Validitas dan Reliabilitas}

Penelitian ini menjaring data dari responden dengan menggunakan instrumen yang valid dan reliabel karena telah lolos uji validitas dan reliabilitas dengan $r>0$ dan nilai Croanbach Alpha $>0,6$. Hasil uji validitas dan reliabikitas dapat dilihat pada tabel dibawah.

Tabel Uji Validitas dan Reliabilitas

\begin{tabular}{|c|c|c|c|c|c|}
\hline & $\begin{array}{l}\text { Scale Mean if } \\
\text { Item Deleted }\end{array}$ & $\begin{array}{c}\text { Scale Variance if } \\
\text { Item Deleted }\end{array}$ & $\begin{array}{l}\text { Corrected ltem- } \\
\text { Total Correlation }\end{array}$ & $\begin{array}{c}\text { Squared Multiple } \\
\text { Correlation }\end{array}$ & $\begin{array}{l}\text { Cronbact's } \\
\text { Alpha if them } \\
\text { Deleted }\end{array}$ \\
\hline P1 & 46,63 & 30,392 &, 406 & 385 & .761 \\
\hline$P_{2}$ & 46,99 & 28,922 & 478 & .394 & .753 \\
\hline P3 & 46,42 & 31,001 &, 323 & .267 & .767 \\
\hline P4 & 46,82 & 29,658 & .455 & .432 & .757 \\
\hline P 5 & 46,81 & 28,842 &, 523 &, 527 &, 750 \\
\hline P6 & 47,26 & 27,530 &, 509 & .439 & .748 \\
\hline P7 & 47,32 & 27,242 &, 610 & .499 & .738 \\
\hline P \& & 46,97 & 29,277 &, 413 & .472 & .759 \\
\hline P 9 & 46,79 & 28,656 & .527 & .507 & .749 \\
\hline P 10 & 47,01 & 29,455 & .400 & .282 & .760 \\
\hline P11 & 48,07 & 27,018 & .378 &, 402 & .768 \\
\hline$P_{12}$ & 46,97 & 28,343 & 541 & .429 & .747 \\
\hline P 13 & 48,08 & 31,716 & .017 & .178 & 816 \\
\hline
\end{tabular}

\section{Pembahasan}

1. Faktor Produk

Faktor pertama disebut faktor produk karena semua variabel yang terdapat dalam faktor ini berkaitan dengan produk yang terdiri dari model produk yang sesuai syariah, model produk bervariasi dengan beragam warna, corak, motif serta up to date, logo Rabbani disetiap produknya, tersedia dari usia anak-anak hingga dewasa dan terbuat dari bahan yang berkualitas sehingga nyaman dikenakan. Berdasarkan teori Kotler (dalam Hidayat, 2012:5) , kelima variabel tersebut merupakan atribut produk Rabbani. Sesuai dengan teori yang diungkapkan oleh Simamora (dalam Hidayat, 2012:5), atribut produk tersebut melekat dan merupakan bagian dari produk Rabbani.

2. Faktor Harga dan Tempat

$$
\text { Teori Palmer }
$$

mengungkapkan bahwa place (tempat) merupakan gabungan antara lokasi dan keputusan atas saluran distribusi, yaitu menyangkut hubungan antara mengkomunikasikan produk kepada konsumen dan lokasi yang strategis. Sesuai dengan teori Palmer, maka dapat dikatakan bahwa lokasi gerai Bunker Rabbani Pucang Surabaya yang strategis merupakan bagian dari place. Fasilitas yang ditawarkan juga turut mempengaruhi konsumen untuk membeli produk Rabbani. Fasilitas merupakan salah satu bagian dari dimensi service quality yaitu bukti fisik (tangibles). Bukti fisik meliputi fasilitas fisik, perlengkapan, pegawai dan sarana komunikasi (Tjiptono, 2005:273).

Faktor lain yang juga mempengaruhi konsumen untuk melakukan keputusan pembelian terhadap produk Rabbani adalah harga. Jika dilihat dari sudut pandang konsumen, harga merupakan indikator nilai bilamana harga tersebut dihubungkan dengan manfaat yang dirasakan atas suatu produk. Nilai (value) adalah rasio perbandingan antara manfaat yang dirasakan dengan harga yang harus dibayarkan (Tjiptono, 1997:151). 
3. Faktor Store Promotion

Faktor ketiga yang mempengaruhi keputusan pembelian konsumen adalah faktor store promotion, yang terdiri dari menjadi member Rabbani dan memiliki kartu keanggotaan, promo diskon untuk member dan non member, serta gerai yang bersih dan display produk menarik. Ketiga variabel ini merupakan bagian dari kegiatan promosi Rabbani. Namun hanya sebatas dilakukan di gerai. Promosi merupakan salah satu cara untuk mempengaruhi konsumen agar melakukan keputusan pembelian. Hal ini sejalan dengan teori Schiffman dan Kanuk (2004:20) yang mengungkapkan bahwa promosi merupakan salah satu usaha pemasaran perusahaan dan menjadi sebuah input bagi konsumen untuk melakukan pengambilan keputusan.

Ketiga faktor yang telah dijelaskan sebelumnya yaitu faktor produk, faktor harga dan tempat serta faktor store promotion yang merupakan bagian dari promosi, adalah bauran pemasaran (marketing mix). E. Jerome (dalam Wulandari, 2012:49) mengungkapkan bahwa bauran pemasaran (marketing mix) adalah sebuah perangkat alat pemasaran taktis yang terkontrol dan dipadukan oleh perusahaan untuk menghasilkan respon yang diinginkan pasar yang terdiri dari empat komponen dasar yaitu product, price, promotion, place (4 P). Berdasarkan hasil penelitian yang telah disesuaikan dengan teori, dapat dikatakan bahwa bauran pemasaran Bunker Rabbani Pucang
Surabaya berhasil karena mampu mempengaruhi konsumen untuk melakukan keputusan pembelian terhadap produk Rabbani. Meskipun untuk faktor promosi masih kurang lengkap karena hanya sebatas pada faktor store promotion.

Jika ditinjau dari sisi unsur manusia yang mempengaruhi karakteristik konsumen muslim, maka dari hasil penelitian dapat dilihat bahwa unsur 'aql, qalb dan nafs mempengaruhi konsumen untuk membeli produk Rabbani. Mean jawaban responden tertinggi pertama menunjukkan bahwa konsumen membeli produk Rabbani karena adanya logo Rabbani pada setiap produknya. Hal ini menjelaskan bahwa konsumen membeli produk Rabbani karena terdorong nafs untuk membeli produk busana muslim yang branded seperti Rabbani.

Jawaban yang memiliki nilai mean tertinggi kedua yaitu sebesar 4,38 adalah indikator model produk Rabbani yang syar'i. Konsumen Rabbani berpikir secara rasional dengan 'aql bahwa berbusana muslim harus menepati aturan syariah. Hal tersebut dapat dipenuhi oleh konsumen apabila mereka mengenakan produk Rabbani. Sehingga dengan berbusana muslim sesuai syariah, akan memperoleh perasaan atau qalb yang tenang.

Berdasarkan penjelasan tersebut, dapat dikatakan bahwa pemahaman konsumen terhadap unsur manusia yaitu 'aql, qalb dan nafsu turut mempengaruhi keputusan pembelian yang diambil oleh konsumen. Manusia menggunakan akal 
untuk memahami teori tentang mode, menggunakan kalbu untuk memahami bahwa berbusana muslim akan terasa nyaman jika menggunakan model busana yang syar'i dan menggunakan nafsu untuk memahami harga sebuah produk, yaitu membeli produk yang bermerek berarti harus membayar harga yang lebih mahal.

\section{Simpulan}

Berdasarkan hasil analisis penelitian, ditemukan tiga faktor yang mempengaruhi keputusan pemebelian konsumen terhadap produk Rabbani di Bunker Rabbani Pucang Surabaya, yaitu faktor produk, faktor harga dan tempat serta faktor store promotion. Faktorfaktor tersebut merupakan bauran pemasaran (marketing mix) dari Rabbani, meskipun untuk faktor promosi masih kurang lengkap karena hanya sebatas faktor store promotion. Sehingga dapat disimpulkan bahwa marketing mix Bunker Rabbani Pucang Surabaya berhasil, karena mampu mempengaruhi konsumen untuk melakukan keputusan pembelian terhadap produk Rabbani. Selain itu, pemahaman konsumen terhadap unsur manusia yaitu 'aql, qalb dan nafs juga turut mempengaruhi konsumen melakukan keputusan pembelian. Konsumen menggunakan akal mereka untuk memahami mode, menggunakan kalbu untuk memahami bagaimana berbusana agar memperoleh perasaan yang tenang dan menggunakan nafsu untuk memahami harga sebuah produk.

\section{Saran}

1. Saran bagi pihak Bunker Rabbani Pucang Surabaya

Pihak Rabbani diharapkan terus menjaga posisi atribut produknya agar tidak kalah bersaing dengan merek-merek baru yang bermunculan. Selain itu juga menjaga kesyar'ian model produknya.

2. Saran bagi peneliti selanjutnya

1) Peneliti selanjutnya dapat melakukan penelitian dengan analisis faktor konfirmatori untuk mengkonfirmasi ketiga faktor yang telah ditemukan dalam penelitian ini.

2) Ketiga faktor yang dihasilkan dalam penelitian ini juga dapat dijadikan sebagai penelitian regresi.

3) Faktor promosi yang dihasilkan dari penelitian ini masih kurang lengkap, karena hanya sebatas faktor store promotion. Sehingga peneliti selanjutnya dapat menggali faktor promosi secara lebih lengkap dan mendalam.

\section{Daftar Referensi}

Al-Quran dan Terjemahnya. 1998. Semarang: Asy Syifa'. 
Burhani, Ruslan. 2012, Perkembangan Fesyen

Muslimah Menggembirakan. Gaya Hidup, Antara News. (Online), (http://www.antaranews.com//, diakses 15 April 2013).

Dartistiana, Nabiya Carissa. 2013. Faktor yang Mempengaruhi Keputusan Mahasiswa Memilih Program Studi SI Ekonomi Islam Fakultas Ekonomi dan Bisnis Universitas Airlangga. Skripsi tidak diterbitkan. Fakultas Ekonomi dan Bisnis Universitas Airlangga.

Dessyana, Cindy J. 2013. Store Atmosphere Pengaruhnya Terhadap Keputusan Pembelian Konsumen Di Texas Chicken Multimart II Manado (Online), Volume 1 Nomor 3 , (http://ejournal.unsrat.ac.id//, diakses 1 Oktober 2013).

Hidayat, Asep Taufik. 2012. Hubungan Antara Atribut Produk dengan Minat Beli Konsumen (Online), Volume 1 Nomor 1 , (http://jurnal.unpad.ac.id//, diakses 20 Desember 2013).

Malhotra, Naresh K. 2009. Riset Pemasaran Pendekatan Terapan Edisi Keempat Jilid Satu. Jakarta: PT Indeks.

Muflih, Muhammad. 2006. Perilaku Konsumen dalam Perspektif IImu Ekonomi Islam. Jakarta: Raja Grafindo Persada.
Palmer, Adrian. 2012. Introduction to Marketing Theory and Practice. Oxford: Oxford University

Press.

Rizan, Mohammad dkk. 2012. Pengaruh Brand Image dan Brand Trust Terhadap Brand Loyalty The Botol Sosro (Online), Volume 3 Nomor 1, (http://www.jrmsi.com//, diakses 1 Oktober 2013).

Santoso, Singgih. 2010. Statistik Multivariat. Jakarta: PT Elex Media Kumputindo.

Schiffman, L.G. and L.L. Kanuk. 2004. Consumer Behavior. New Jersey : Pearson Prentice Hall.

Sebayang, Muly Kata dan Simon Darman O. Siahaan. 2008. Pengaruh Celebrity Endorsesr Terhadap Keputusan Pembelian Sepeda Motor Merek Yamaha Mio pada Mio Automatic Club (MAC) Medan (Online), Volume 1 Nomor 3, (http://usupress.usu.ac.id//, diakses 28 September 2013).

Tjiptono, Fandy. 1997. Strategi Pemasaran. Yogyakarta: Penerbit Andi. 2005. Pemasaran Jasa. Malang: Bayumedia.

Velany, Aisyah. 2008. Pengaruh Cause Related Markering (CRM) Terhadap Loyalitas Pelanggan Air Minum Dalam Kemasan (AMDK) Merek Aqua pada Mahasiswa Sarjana Reguler Universitas Indonesia. Tesis tidak diterbitkan. 
Fakultas IImu Sosial dan IImu Politik Universitas Indonesia.

Widagdo, Herry. 2011. Analisis Pengaruh Kualitas Layanan dan Promosi Terhadap Keputusan Konsumen Membeli Komputer pada PT XYZ Palembang (Online), Volume 1 Nomor 1 ,

(http://eprints.mdp.ac.id//, diakses 29 September 2013).

Wulandari, Wahju. 2012. Pengaruh Marketing Mix Terhadap Keputusan Pembelian Pada Waserda UKM Mart Koperasi Karyawan Widyagama Malang (Online). Volume 1 Nomor 3, (http://widyagama.ac.id/ejournal/ I, diakses 1 Oktober 2013).

Yusrizal. 2008. Pengujian Validitas Konstruk dengan Menggunakan Analisis Faktor ( Online), Volume 5 Nomor 1 , (http://digilib.unimed.ac.id//, diakses 27 September 2013). 